\title{
ANALISIS TATA KELOLA TEKNOLOGI INFORMASI PADA TVRI PAPUA MENGGUNAKAN COBIT 5.0 DOMAIN MEA
}

\author{
Mario Hendrick Hassor $\left(^{1)}\right.$ dan Melkior N. N. Sitokdana $\left(^{2)}\right.$ \\ ${ }^{1,2}$ Teknologi Informasi, Universitas Kristen Satya Wacana \\ ${ }^{1,2}$ Jl. Blotongan, Sidorejo Lor, Sidorejo, Kota Salatiga, Jawa Tengah 50714 \\ E-mail : 682015041@ student.uksw.edu ${ }^{1)}$, melkior.sitokdana@uksw.edu ${ }^{2)}$
}

\begin{abstract}
ABSTRAK
TVRI Papua Kota Jayapura telah menerapkan TI dalam proses operasionalnya seperti sistem informasi FileZilla. Tata Kelola Teknologi Informasi pada TVRI Papua pada bidang pemberitaan menggunakan framework COBIT 5 berdasarkan data yang diperoleh yang menghasilkan tingkat kematangan pada domain 3 MEA yang berbeda-beda. MEA01 (Monitoring, Evaluasi dan Penilaian Kinerja dan Kesesuaian), berada pada tingkat kematangan level 2 Managed Process bahwa kinerja TI-nya sudah standard dan berjalan dengan baik. MEA02 (Monitoring, Evaluasi dan Penilaian Sistem Kontrol Internal), berada pada tingkat kematangan level 3 Established Process bahwa pengendalian sepenuhnya berjalan sesuai dengan strategis organisasi Tugas Pokok dan Fungsi (Tupoksi). MEA03 (Monitoring, Evaluasi dan Penilaian Kepatuhan dan Persyaratan Eksternal), berada pada tingkat kematangan level 2 (Managed Process) dimana proses TI maupun proses bisnis sesuai dengan hukum serta kebijakan yang diterapkan. Dalam hal ini TVRI Papua Kota Jayapura agar lebih efisien dalam penggunaan TI diperlukan beberapa penanganan sehingga penggunaan FileZilla sesuai dengan strategis organisasi Tugas Pokok dan Fungsi (Tupoksi).
\end{abstract}

Kata Kunci : Tata Kelola Teknologi Informasi, Frameworks, COBIT 5

\section{PENDAhuluan}

Perkembangan teknologi informasi kini menjadi kebutuhan sehari-hari bagi perusahaan maupun pemerintahan di Indonesia dan menjadi pendukung untuk mencapai sebuah tujuan dalam perusahaan maupun pemerintahan. Pemanfaatan teknologi informasi saat ini dilakukan oleh banyak perusahaan profit maupun nonprofit dan organisasi lainnya. Selain pemanfaatan, penerapan TI juga perlu mekanisme tata kelola TI yang baik untuk melakukan pengawasan secara menyeluruh agar tujuan bisnis suatu organisasi benar-benar dapat dicapai secara efektif dan efisien (Wiraniagara \& Wijaya 2019). Sehinga teknologi informasi akan mendapatkan hasil yang efektif apabila menggunakan tata kelola yang baik, maka pemanfaatan, serta pengawasan dalam penggunaannya mampu dinilai dengan baik (Umar, 2019). Dalam melakukan penerapan teknologi informasi (TI) di suatu organisasi membutuhkan investasi yang besar dan ada pula risiko yang tinggi, sehingga adanya pengawasan secara menyeluruh dengan mekanisme tata kelola yang tepat dan benar terhadap pemanfaatan TI serta adanya evaluasi kinerja TI agar mekanisme manajemen TI berjalan sesuai tujuan dan proses bisnis dalam organisasi pemerintah yang berlaku. Penggunaan TI akan bermanfaat jika penerapannya sesuai dengan tujuan, visi dan misi yang telah ditetapkan dalam suatu organisasi dan diterjemahkan dalam rencana strategi perusahaan maupun organisasi akan tercapai jika rencana dan strategis TI diimplementasikan (Ardiyasa, 2019).

Dalam suatu organisasi evaluasi di perlukan untuk perkembangan teknologi informasi yang di terapkan agar berkontribusi dalam organisasi secara maksimal, ada beberapa Framework yang bisa diperlukan untuk melakukan evaluasi untuk pengendalian standar teknologi diantaranya ISO, COBIT, atau ITIL (Ajismanto, 2018). COBIT 5.0 merupakan framework yang digunakan sebagai penelitian ini, guna dalam model framework tata kelola TI yang mencakup masalah operasional, implementasi, perencanaan dan pengawasan setiap proses TI.

TVRI Papua merupakan salah satu stasiun televisi daerah di provinsi Papua yang didirikan oleh Televisi Republik Indonesia. TVRI Papua didirikan pada 23 Februari 1993 dengan nama TVRI Jayapura. TVRI Jayapura merupakan salah satu instansi yang menerapkan TI pada proses operasionalnya. Lembaga TVRI sendiri pada saat ini mulai menyandingkan antara visi misi lembaga dengan teknologi yang ada, maka dari itu diperlukan perencanaan dan penerapan yang baik dalam menyambut teknologi itu sendiri. Dengan adanya TI pada TVRI Jayapura sehingga perlu pemelihara dan diawasi dengan baik. Salah satu cara yang dilakukan agar dapat mengetahui hal tersebut adalah melakukan Analisis sistem informasi menggunakan framework COBIT 5. oleh karena itu penelitian ini menggunakan COBIT 5 dengan domain MEA agar dapat melihat risiko-risiko yang ada juga keuntungan dalam investasi TI

Penelitian - penelitian sebelumnya telah banyak membahas tentang Teknologi Informasi (TI) salah satunya tentang Evaluasi Tata Kelola Teknologi Informasi Dengan Framework COBIT 5, disimpulkan bahwa sistem pengelolaan TI masih lemah. Namun, pada 
domain APO dengan nilai rata-rata 4, menunjukkan bahwa sistem manajemen TI sudah berjalan baik tetapi tetap harus dikembangkan. Hasil nilai yang lemah terdapat pada $A P O$ subdomain $A P O 13$ yang hanya mampu memperoleh nilai rata-rata 2.38 menunjukkan masih adanya kelemahan dalam penangan keamanan dalam pengelolaan TI. Hal ini akan mengganggu distribusi data dan kinerja pengguna dan hasil penelitian evaluasi pada domain BAI dengan target capaian 3 menunjukkan hampir semuanya memenuhi syarat (Suharto, 2016).

Audit Tata Kelola Teknologi Informasi Menggunakan Framework COBIT 5 (studi kasus pada Balai Besar Perikanan Budidaya Laut Lampung) hasil penelitian menemukan bahwa pada proses semua proses EDM03, APO12, APO13, BAIO6, DSSO1, DSSO2, DSSO3, DSS05, MEA01, MEA02. Kesepuluh proses ini hanya mampu memperoleh nilai rata-rata 2,8 artinya masih pada level Defined process. Beberapa kelemahan yang paling fatal adalah belum memiliki prosedur yang baku dalam proses pengamanan data dan informasi, sehingga perlunya rekomendasi untuk mencapai tujuan yang diharapkan (Suryono, 2018).

Analisis Dan Penilaian Teknologi Informasi Pada Proses Tata Kelola Dengan COBIT 5 Pada Domain EDM Studi Kasus Universitas Peradaban bahwa hasil penilaian menggunakan pendekatan capability level COBIT 5 menunjukkan bahwa Puksi Universitas Peradaban memiliki capability level pada Level 1 untuk proses EDM01; Ada gap yang cukup signifikan antara keinginan atau target dengan kondisi di lapangan Penelitian selanjutnya (Haryono, 2019). Meskipun beberapa responden menyatakan pada level tertentu sudah memenuhi kriteria, namun pada level sebelumnya yaitu Level 1 masih terdapat kriteria yang belum terpenuhi karena menurut penilaian ISO/IEC 15504 pada COBIT 5, level kapabilitas hanya akan didapatkan jika level sebelumnya telah terpenuhi secara sempurna. Analisis Kinerja Tata Kelola Teknologi Informasi Pada Dinas Perpustakaan Dan Kearsipan Daerah Kota Salatiga Menggunakan Framework COBIT 5.0, menghasilkan tingkat kematangan yang berbeda-beda pada domain MEA. Maka itu Agar dapat mencapai target yang diinginkan oleh Dinas Perpustakaan dan Kearsipan Daerah Kota Salatiga dalam penanganan peningkatan kinerja TI untuk semua karyawan pada pengoperasian aplikasi Slims, perlu diadakannya pelatihan bagi staff pegawai yang ada. Dari hasil penelitian sebelumnya yang telah dibahas, peneliti menilai bahwa framework COBIT 5 sangat membantu instansi dalam penilaian kinerja TI dan sebagai pengambilan keputusan untuk mencapai tujuan suatu instansi (Rumere Harold, 2020).

\section{RUANG LINGKUP}

Ruang lingkup penelitian ini mencakup sebagai berikut:

1. Cakupan permasalahannya adalah terdapat berbagai masalah yang sering terjadi di TVRI Jayapura, terutama penanganan dalam sistem aplikasi yang di gunakan. Oleh karena itu dilakukan analisis kinerja tata kelola teknologi informasi menggunakan framework COBIT 5.

2. Batasan penelitian ini adalah hanya focus menganalisis kinerja tata kelola menggunakan framework COBIT 5 dengan domain MEA.

3. Hasil yang di dapatkan dari penelitian ini dapat digunakan untuk mengidentifikasi risiko-risiko dan rekomendasi penanganan risiko sesuai dengan framework COBIT 5.

\section{BAHAN DAN METODE}

Berikut penjelasan teori yang dipakai untuk menunjang penelitian serta penjelasan metode yang digunakan dalam penelitian ini.

\subsection{Audit Tata Kelola Teknologi Informasi}

Teknologi informasi secara umum adalah suatu studi tentang perencanaan, pengembangan, implementasi, dukungan atau manajemen sistem informasi dengan basis komputer, terutama pada perangkat keras ataupun perangkat lunak. teknologi informasi pada umum di bidang teknologi di manfaatkan agar bisa membantu manusia dalam mengubah, membuat, menyimpan, mengomunikasikan, dan juga menyebarkan sejumlah informasi penting mulai dari tiap personal pribadi, kelompok, maupun perusahaan di dunia ini. Pengertian lain tentang yang di kenal adalah: "IT governance is the responsibility of executives and the board of directors, and consists of the leadership, organisational structures and processes that ensure that the enterprise's IT sustains and extends the organisation's strategies and objectives. "(ISACA, 2012). Maksud dari pengertian ini adalah tata kelola teknologi informasi merupakan sebuah tanggung jawab eksekutif dan peran dewan direksi sehingga bagian yang tidak bisa dipisahkan dari tata kelola suatu perusahaan dan terdiri dari struktur kepemimpinan dalam organisasi dengan proses yang dipastikan bahwa TI membantu dan memperlebar strategi dalam tujuan organisasi. Tata kelola TI sebagai salah satu faktor penentu keberhasilan pencapaian tujuan dalam strategi perusahaan (Rahayu and Agitha, 2019).

Peran Teknologi Informasi merupakan sarana dan prasaran (hardware, software, use ware) sistem dan metode untuk memperoleh, mengirimkan, mengolah, menafsirkan, menyimpan, serta mengorganisasikan, dan menggunakan data secara bermakna.(Rumere Harold, 2020). Tata kelola TI perlu dilakukan evaluasi pada sebuah instansi. Hal ini ditujukan untuk mengetahui Teknologi Informasi yang telah ditetapkan dan pemahaman implementasi TI dalam mencapai tujuan instansi termasuk dengan proses bisnis, arsitektur TI, organisasi dan rencana pengembangan TI (Pasha, 2020). Sehingga dapat disimpulkan bahwa peran tata kelola teknologi informasi ini sangat penting dalam perencanaan, pengembangan manajemen dalam sistem informasi berbasis komputer dan sebagai pengambilan 
keputusan dalam mencapai tujuan organisasi. Tata kelola TI juga dapat dikatakan sebagai framework dalam tujuan serta membantu pengambilan keputusan dalam perusahaan dalam manfaat teknologi informasi.

COBIT 5 (Control Objectives For Information and Related Technology) merupakan salah satu kerangka kerja framework dalam mendukung tata kelola teknologi informasi. COBIT 5 Control Objectives For Information and Related Technology) didefinisikan sebagai sekumpulan kerangka kerja untuk mendukung pengelolaan teknologi informasi (IT Management) dan mendukung tujuan organisasi serta meningkatkan kepercayaan pemilik bisnis, TI mengenai nilai informasi serta aset dari teknologi informasi (Prasojo dan Pujiono, 2017). COBIT 5 mulai diterbitkan pada tahun 1996 oleh Information System Audit And Control Asociation (ISACA) dan IT Governance Institute (ITGI) yang membantu auditor, manajemen dan pemilik bisnis untuk menjembatani kesenjangan (gap) antara risiko bisnis maupun masalah-masalah teknis yang ada pada organisasi yang bersangkutan (Suryono dkk, 2018) .COBIT 5 menggunakan praktik tata kelola dan manajemen untuk menjelaskan tindakan praktik yang baik untuk efek tata kelola dan manajemen lebih perusahaan IT (Suryono, 2018). COBIT mendukung tata kelola TI dengan menyediakan kerangka kerja untuk mengatur keselarasan TI dengan bisnis. Kerangka kerja juga memastikan bahwa TI dapat memungkinkan bisnis, memaksimalkan keuntungan, dan risiko TI dikelola secara tepat serta sumber daya TI yang digunakan secara bertanggung jawab (Pramita Ady, 2019). Tingkat Kapabilitas Proses berdasarkan pada ISO/IEC 15504 mengenai Software Engineering dan Process Assessment (Pramita Ady, dkk, 2019). Pada COBIT 5 terdapat enam tingkat antara lain:

1. Level 0, Incomplete Process

Pada proses ini tidak diimplementasikan atau gagal dalam mencapai tujuan prosesnya. Pada level ini tidak ada bukti dari setiap pencapaian sistematis tujuan proses.

2. Level 1, Performed Process

Proses implementasi mencapai tujuan prosesnya.

3. Level 2, Managed Process

Proses yang dilakukan implementasi dengan cara dikelola (direncanakan, dimonitor, dan disesuaikan) dan hasilnya ditetapkan kontrol.

4. Level 3, Established Process

Proses didokumentasikan dan mengomunikasikan (untuk efisiensi organisasi)

5. Level 4, Predictable Process

Proses dimonitor, diukur, dan diprediksi demi mencapai hasil.

6. Level 5, Optimizing Process,

Proses diprediksi, ditingkatkan dengan tujuan bisnis yang relevan serta tujuan yang akan datang.

Berikut ini pada gambar 1 merupakan prinsipprinsip framework COBIT 5.
Gambar 1. Prinsip-Prinsip Framework COBIT 5

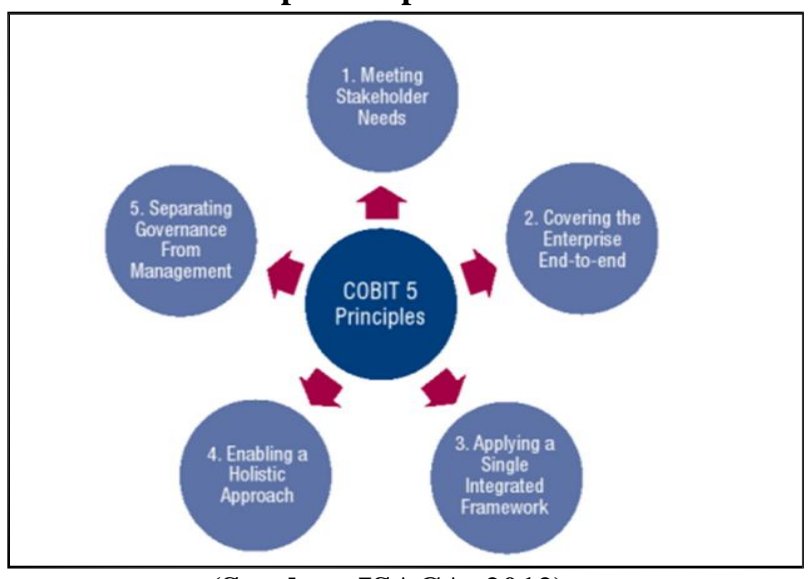

(Sumber: ISACA, 2012)

\section{PEMBAHASAN}

Pada tahap ini akan mengukur tingkat kematangan pada TVRI Papua Kota Jayapura berdasarkan hasil wawancara, observasi di bagian pemberitaan terkait menggunakan COBIT 5 dengan menggunakan satu domain yaitu domain Monitor, Evaluate and Assess (MEA). Domain ini terdiri atas 3 kontrol objektif yang berfokus pada manajemen dengan proses penilaian kebutuhan perusahaan dan sistem yang sedang berjalan masih memenuhi atau tidak, memastikan desain kontrol. Menurut ISACA, COBIT 5 terdiri dari 5 domain yaitu :

1. Domain Evaluate, Direct, and Monitor (EDM)

Evaluate, Direct, and Monitor (EDM), Proses EDM berurusan dengan pemangku kepentingan dalam melakukan sebuah penilaian. Untuk mengoptimalkan risiko serta sumber daya dan mencakup kegiatan atau praktik yang dilakukan guna mengevaluasi pilihan strategis dan memberikan arahan serta hasil pemantauan nya pada TI.

2. Align, Plan and Organize (APO)

Align, Plan and Organize (APO), Membantu mengarahkan dan memberikan dukungan bagi domain BAI dan DSS. Domain ini berjalan pada strategi dan taktik serta mengidentifikasi risiko pada TI agar dapat berkontribusi pada pencapaian tujuan bisnis. Build, Acquire and Implement (BAI), Domain ini lebih kepada menciptakan, memperoleh, dan mengimplementasikan sistem yang berjalan sesuai dengan proses atau tujuan bisnis.

3. Build, Acquire and Implement (BAI)

Build, Acquire and implement (BAI), Memberikan solusi dan melewatinya sehingga akan berubah menjadi layanan. Demi mewujudkan strategi TI, solusi TI perlu diidentifikasi, dikembangkan atau diperoleh, serta diimplementasikan dan terintegrasi ke dalam proses bisnis. Perubahan dan pemeliharaan sistem yang ada juga dicakup oleh domain ini, untuk memastikan bahwa solusi terus memenuhi tujuan bisnis. 
4. Deliver, Service, and Support (DSS)

Deliver, Service, and Support (DSS), meliputi mengirimkan, layanan, dan dukungan atau memberi pelayanan yang aktual bagi bisnis, termasuk manajemen data dan proteksi informasi yang berhubungan dengan proses bisnis. Monitor, Evaluate and Assess (MEA), Terfokus pada manajemen guna melakukan penilaian kebutuhan perusahaan atau organisasi pada sistem sudah memenuhi atau tidak, dan memastikan desain kontol sudah mengikuti regulasi, serta monitoring yang berkaitan dengan penilaian efektivitas sebuah sistem.

5. Monitor, Evaluate and Assess (MEA)

Domain Monitor, Evaluate and Assess (MEA) yaitu berfokus pada area manajemen yaitu proses penilaian kebutuhan perusahaan dan sistem yang sedang berjalan masih memenuhi atau tidak, memastikan desain kontrol mematuhi regulasi, serta monitoring berkaitan dengan penilaian independen efektivitas sistem serta kemampuan untuk memenuhi bisnis objektif oleh penilai independen. Domain MEA terdiri dari 3 control objective antara lain :

1) MEA 1 Memantau, Mengevaluasi, dan Menilai Kinerja dan Kesesuaian

Mengumpulkan, memvalidasi dan mengevaluasi bisnis, TI dan tujuan proses dan metrik. Memantau bahwa proses yang melakukan terhadap kinerja yang disepakati dan tujuan konformitas dan metrik serta memberikan pelaporan yang sistematis dan tepat waktu. Pernyataan tujuan proses MEA 1 yaitu memberikan transparansi kinerja dan kesesuaian dan mendorong pencapaian tujuan.

2) MEA 2 Memantau, Mengevaluasi, dan Menilai Sistem Kontrol Internal

Terus memantau dan mengevaluasi lingkungan kontrol, termasuk penilaian diri dan tinjauan jaminan independen. Memungkinkan manajemen untuk Mengidentifikasi kekurangan kontrol dan inefisiensi dan untuk memulai tindakan perbaikan. Merencanakan, mengatur dan memelihara standar untuk penilaian pengendalian internal dan kegiatan jaminan. Tujuan proses MEA 2 yaitu memperoleh transparansi bagi para pemangku kepentingan utama tentang kecukupan sistem pengendalian internal dan dengan demikian memberikan kepercayaan dalam operasi serta kepercayaan pada pencapaian tujuan perusahaan dan pemahaman yang memadai tentang risiko residual.

3) MEA 3 Memantau, Mengevaluasi, dan Menilai Kepatuhan terhadap Persyaratan Eksternal.

Mengevaluasi bahwa proses TI dan proses bisnis yang didukung TI sesuai dengan hukum, peraturan dan persyaratan kontrak. Dapatkan jaminan bahwa persyaratan telah diidentifikasi dan dipatuhi, dan mengintegrasikan kepatuhan TI dengan kepatuhan perusahaan secara keseluruhan. Sehingga tujuan dari proses MEA 3 adalah memastikan bahwa perusahaan mematuhi semua persyaratan eksternal yang berlaku.

\subsection{Metode Penelitian}

Penelitian ini mengambil objek pada TVRI Jayapura bagian pemberitaan di Kota Jayapura, Papua. Penelitian ini menggunakan pendekatan deskriptif kualitatif dengan tujuan untuk menemukan fenomenafenomena atau kejadian serta fakta yang ada pada kantor TVRI Jayapura khususnya bidang Pemberitaan. Dan dalam penelitian ini peneliti menggunakan satu domain COBIT, yaitu domain MEA dan akan berfokus pada area manajemen sebagai proses penilaian kebutuhan perusahaan/organisasi, apakah sudah mencapai standar sesuai kebijakan yang ditetapkan atau belum. Berikut ini merupakan alir penelitian.

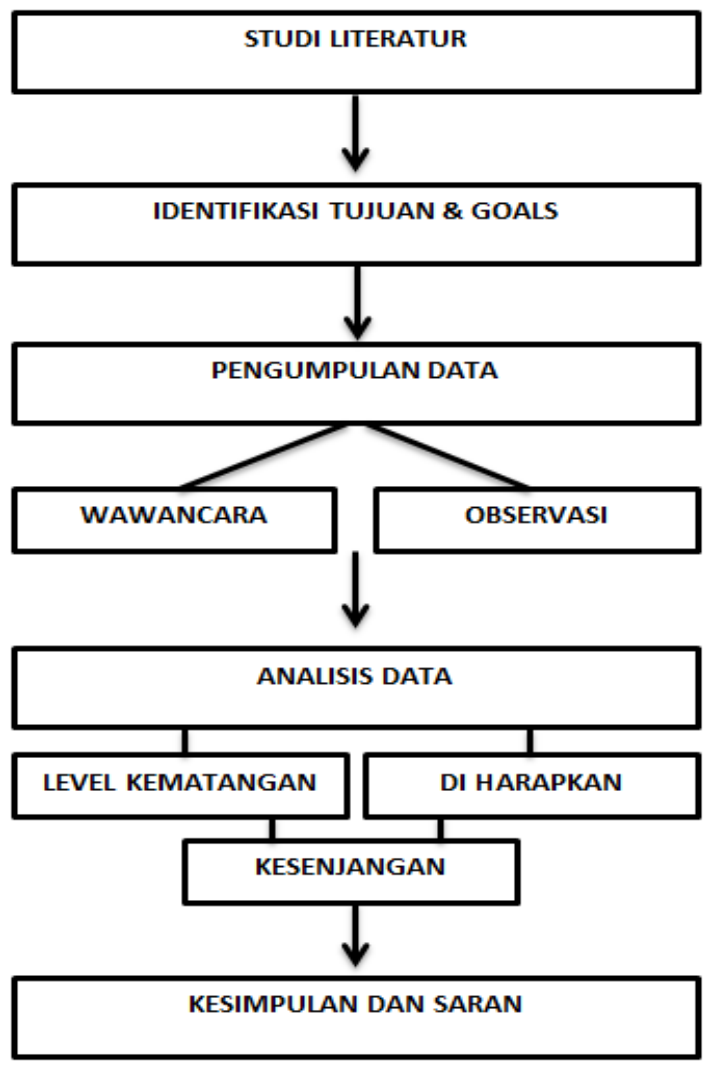

Gambar 2. Alir Penelitian

Tahapan penelitian pada Gambar 2 dapat dijelaskan sebagai berikut:

1. Tahap ini merupakan tahap pertama untuk mempelajari pustaka/studi literatur mengenai COBIT Framework dan tahap evaluasi kinerja tata kelola TI pada TVRI Papua bidang pemberitaan. 
2. Pada tahap ini peneliti mengidentifikasi atau melakukan pemetaan Enterprise Goals, IT-Related Goals, dan IT-Process dari visi dan misi TVRI Papua

3. Pada tahap ketiga pengumpulan data dilakukan wawancara dan observasi di TVRI Papua selama 6 bulan dengan menentukan narasumber sesuai kebutuhan dalam menjawab pertanyaan wawancara. Adapun pemilihan narasumber sesuai dengan keterkaitan langsung pada bagian pemberitaan TVRI Papua, agar melihat dan mengamati proses bisnis serta penggunaan aplikasi FileZilla.

4. Pada tahap keempat melakukan analisis wawancara terhadap sistem informasi yang mengacu pada COBIT Framework, hasil wawancara berupa transkrip wawancara yang dilakukan perhitungan untuk tingkat maturity pada sistem di TVRI Papua Jayapura.

5. Pada tahap kelima merupakan tahap terakhir menarik kesimpulan dari laporan hasil Domain MEA dari kerangka kerja COBIT 5.
Pada penelitian ini dibuat tabel RACI pada tabel 1, untuk mengidentifikasi peran dan responden dalam menyelesaikan masalah, RACI adalah singkatan dari Responsible, Accountable, Consulted, dan Informed. Secara sederhana RACI menerangkan siapa saja yang terlibat dalam suatu tindakan pada sebuah organisasi baik perusahaan maupun pemerintahan.

Tabel 1. Tabel RACI

\begin{tabular}{|c|c|c|}
\hline RACI & Peran & Responden \\
\hline Responsible & $\begin{array}{c}\text { Memantau aktivitas dalam } \\
\text { media pemberitaan }\end{array}$ & $\begin{array}{c}\text { Kepala seksi } \\
\text { Pemberitaan }\end{array}$ \\
\hline Accountable & $\begin{array}{c}\text { Wewenang dalam berita } \\
\text { daerah }\end{array}$ & $\begin{array}{c}\text { Pemberitaan } \\
\text { Daerah }\end{array}$ \\
\hline Consulted & $\begin{array}{c}\text { Memberikan pendapat atau } \\
\text { saran dalam pemberitaan }\end{array}$ & $\begin{array}{c}\text { Kepala } \\
\text { teknik }\end{array}$ \\
\hline Informed & $\begin{array}{c}\text { Melihat kemajuan dalam } \\
\text { aktivitas pemberitaan }\end{array}$ & $\begin{array}{c}\text { Pegawai } \\
\text { ruang } \\
\text { Pemberitaan }\end{array}$ \\
\hline
\end{tabular}

\section{PEMBAHASAN}

Dapat dilihat Tabel 2 merupakan rangkuman pemetaan dari tujuan bisnis TVRI Papua ke dalam Enterprise Goals, dimana mendapatkan 4 Enterprise Goals terpilih yaitu EG4 "Kepatuhan terhadap hukum dan peraturan eksternal", EG7 "Kesinambungan dan ketersediaan layanan bisnis", EG11 "Optimalisasi fungsionalitas proses bisnis", dan EG16 "Orang yang terampil dan termotivasi”.

Tabel 2. Pemetaan Enterprise Goals

\begin{tabular}{|l|l|l|l|}
\hline Perspektif & Kode & \multicolumn{1}{|c|}{ Enterprise Goals COBIT 5 } & Tujuan bisnis \\
\hline Financial & EG4 & $\begin{array}{l}\text { Kepatuhan terhadap hukum dan } \\
\text { peraturan eksternal }\end{array}$ & $\begin{array}{l}\text { Mengoptimalkan pemanfaatan aset, meningkatkan } \\
\text { pendapatan siaran iklan, dan usaha lain terkait } \\
\text { penyelenggaraan penyiaran, serta pengembangan bisnis } \\
\text { sesuai peraturan perundang-undangan. }\end{array}$ \\
\hline Costumer & EG7 & $\begin{array}{l}\text { Kesinambungan dan ketersediaan } \\
\text { layanan bisnis }\end{array}$ & $\begin{array}{l}\text { Menyelenggara program siaran yang terpercaya, } \\
\text { memotivasi, dan memberdayakan yang menguatkan } \\
\text { kesatuan dan keberagaman guna meningkatkan martabat } \\
\text { bangsa. }\end{array}$ \\
\hline Internal & EG11 & $\begin{array}{l}\text { Optimalisasi fungsionalitas proses } \\
\text { bisnis }\end{array}$ & $\begin{array}{l}\text { Menyelenggarakan penyiaran berbasis digital } \\
\text { konvergensi dalam bentuk layanan multiplatform dengan } \\
\text { menggunakan teknologi terkini, yang dikelola secara } \\
\text { modern dan tepat guna, serta dapat diakses secara global. }\end{array}$ \\
\hline $\begin{array}{l}\text { Learning \& } \\
\text { Growth }\end{array}$ & EG16 & Orang yang terampil dan termotivasi & $\begin{array}{l}\text { Menyelenggarakan tata kelola sumber daya manusia } \\
\text { yang berkualitas, kompeten, kreatif dan memiliki etika } \\
\text { secara transparan berbasis meritokrasi, serta } \\
\text { mencerminkan keberagaman. }\end{array}$ \\
\hline
\end{tabular}

Berikutnya dari Enterprise Goals terpilih dilakukan pemetaan lagi pada IT-Related Goals dimana mendapatkan beberapa Related Goals $(R G)$ pada tabel 3 yaitu, RG2 "Kepatuhan dan dukungan TI untuk kepatuhan bisnis terhadap hukum dan peraturan eksternal", RG8 "Penggunaan aplikasi, informasi dan solusi teknologi yang memadai", RG10 "Keamanan informasi, pemrosesan infrastruktur dan aplikasi”, RG11 "Optimalisasi aset, sumber daya, dan kapabilitas TI", RG16 "Personil bisnis dan TI yang kompeten dan termotivasi" 
Tabel 3. Pemetaan Enterprise Goals to IT-Related Goals

\begin{tabular}{|c|l|}
\hline $\begin{array}{c}\text { Enterprise } \\
\text { Goals }\end{array}$ & \multicolumn{1}{c|}{ IT-Related Goals } \\
\hline EG4 & $\begin{array}{l}\text { RG2. Kepatuhan dan dukungan TI untuk } \\
\text { kepatuhan bisnis terhadap hukum dan } \\
\text { peraturan eksternal }\end{array}$ \\
\hline EG7 & $\begin{array}{l}\text { RG8. Penggunaan aplikasi, informasi dan } \\
\text { solusi teknologi yang memadai }\end{array}$ \\
\hline EG11 & $\begin{array}{l}\text { RG10. Keamanan informasi, pemrosesan } \\
\text { infrastruktur dan aplikasi } \\
\text { RG11. Optimalisasi aset, sumber daya, dan } \\
\text { kapabilitas TI }\end{array}$ \\
\hline EG16 & $\begin{array}{l}\text { RG16. Personil bisnis dan TI yang kompeten } \\
\text { dan termotivasi }\end{array}$ \\
\hline
\end{tabular}

Setelah itu dilakukan lagi pemetaan IT Process dari IT Related Goals terpilih sesuai dengan Appendix C dimana mendapatkan beberapa domain yang dapat dilihat dalam tabel 4. Namun di sini peneliti akan menggunakan domain MEA sebagai fokus penelitian.

Tabel 4. Pemetaan IT-Related Goals To IT-Process

\begin{tabular}{|c|l|}
\hline ITRG & \multicolumn{1}{|c|}{ IT Process } \\
\hline RG2 & BAI10, DSS05, MEA02, MEA03 \\
\hline RG8 & BAI05, BAI07 \\
\hline RG10, & BAI06, DSS05, BAI04, \\
RG11 & BAI09,BAI10,DSS01, MEA01 \\
\hline RG16 & \\
\hline
\end{tabular}

Pada tahap ini akan mengukur tingkat kematangan pada TVRI Jayapura Kota Jayapura berdasarkan hasil wawancara, observasi di bagian pemberitaan terkait menggunakan COBIT 5 dengan menggunakan satu domain yaitu domain Monitor, Evaluate and Assess (MEA). Domain ini terdiri atas 3 kontrol objektif yang berfokus pada manajemen dengan proses penilaian kebutuhan perusahaan dan sistem yang sedang berjalan masih memenuhi atau tidak, memastikan desain kontrol mematuhi regulasi, serta monitoring yang berkaitan dengan penilaian independen efektivitas sistem. Pemetaan kondisi saat ini TVRI Jayapura pada bidang pemberitaan Kota Jayapura dilakukan dengan proses wawancara mengenai proses MEA Framework COBIT 5 dengan narasumber. Narasumber wawancara ditentukan berdasarkan posisi, jabatan serta tanggung jawab yang berkaitan dengan proses-proses di MEA untuk aplikasi FileZilla.

\subsection{MEA01-Monitor, Evaluate, and Assess Performance and Conformance \\ Evaluasi pada kinerja TI khususnya aplikasi} FileZilla di TVRI Jayapura bidang pemberitaan dengan melalukan pemetaan antara tujuan bisnis dan tujuan TI, Teknologi Informasi dan strategi Pemberitaan masih standar dan berjalan dengan baik, seperti yang di sampaikan oleh Bapak Origenes Hassor dari pemberitaan TVRI Jayapura menjelaskan: "Alat tersebut untuk mengirimkan data berita ke server/mengeluarkan data berita langsung $k e$ server berita untuk disiarkan termasuk ke telepromter untuk dibaca penyiar berita."

FileZilla telah sesuai standar nasional hal ini dinyatakan bahwa penerimaan berita maupun pengiriman berita antar pusat kantor TVRI dilakukan melalui FileZilla. Namun pengelolaan FileZilla mempunyai kendala seperti gangguan jaringan internet dan listrik sehingga solusi yang sering digunakan ialah melakukan copy data berita lalu di save pada server berita. Adapun yang terlibat dalam penggunaan FileZilla adalah pegawai bagian pemberitaan dan yang bertanggungjawab dalam keamanan aplikasi FileZilla selain seksi teknik termasuk juga seksi pemberitaan.

Berdasarkan hasil percakapan dengan Bapak Origenes Hassor dari TVRI Jayapura bagian pemberitaan Kota Jayapura dapat dikatakan bahwa kinerja TI-nya sudah standard dan berjalan dengan baik, sehingga diharapkan FileZilla dapat digunakan sebaik mungkin sesuai standard kebijakan yang telah ditetapkan. Sehingga tingkat kapabilitas proses berdasarkan COBIT 5, TVRI Jayapura pada bidang pemberitaan telah ada pada level 2 Managed Process.

\subsection{MEA02 - Monitor, Evaluate and Assess the System of the Internal Control}

Pengendalian internal pada TVRI Jayapura di bagian pemberitaan Kota untuk mengatur dan menjaga standar untuk kegiatan penilaian pengendalian internal dan jaminan. Untuk melakukan akses pada FileZilla terdapat username dan password agar dapat mengakses FileZilla tersebut. Seperti yang di sampaikan oleh Bapak Origenes Hassor dari pemberitaan menjelaskan bahwa: "ketika mengakses FileZilla terdapat satu username dan satu password dan tidak diketahui oleh banyak pegawai, hanya diberikan kepada beberapa pegawai yang diberikan tugas dan tanggungjawab".

Pemantauan dan peningkatan control pada FileZilla dilakukan secara tepat waktu dan memperbaharui khususnya pada jaringan sistem dan dilakukan oleh bagian IT. Standarisasi kinerja dipakai oleh TVRI Jayapura di bagian pemberitaan ialah Tugas Pokok dan Fungsi (Tupoksi), serta dilakukan rapat koordinasi manajemen dengan tujuan meminimalisasi hal-hal yang tidak diinginkan dan disesuaikan dengan peraturan baru.

Berdasarkan hasil percakapan dengan Bapak Origenes Hassor dari pemberitaan TVRI Jayapura Kota Jayapura dapat di katakan untuk pengendalian internal nya saat ini tidak semua bisa melakukan akses FileZilla pengolahan harus yang memiliki username dan password serta standar kinerja yang dipakai dan disesuaikan dengan peraturan baru. Maka dapat dikatakan bahwa TVRI Jayapura pada bagian pemberitaan memiliki pengendalian internal untuk mengatur dan menjaga standar kegiatan. Dengan demikian tingkat kapabilitas proses berdasarkan COBIT 5, TVRI Jayapura pada bagian pemberitaan Kota Jayapura telah ada pada level 3 Established Process. 


\subsection{MEA03-Monitor, Evaluate, and Assess}

Compliance with External Requirements

Pada proses ini menilai bahwa proses TI dan proses bisnis TI dengan hukum yang berlaku pada TVRI Jayapura di bagian pemberitaan Kota Jayapura tingkat kematangan TI pada aplikasi yang digunakan. Seperti yang disampaikan oleh Bapak Origenes Hassor di bagian pemberitaan bahwa: "Hukum maupun aturan yang berlaku dikantor dan terus melakukan koordinasi baik pimpinan maupun bawahan".

Terkait hukum yang berlaku dengan TI selama ini belum ada masalah, ketika ada masalah langsung diselesaikan oleh pimpinan melalui rapat koordinasi sekaligus menampung masukan maupun saran dari masing-masing bidang demi kemajuan siaran TVRI Jayapura untuk ke depannya. Berdasarkan hasil pernyataan Bapak Origenes Hassor di bagian pemberitaan TVRI Jayapura Kota Jayapura dapat dikatakan untuk proses TI dan proses bisnis TI dengan hukum serta kebijakan yang telah diberlakukan bahwa telah standar dilakukan juga pada aplikasi yang digunakan. Berdasarkan pembahasan di atas, tingkat kapabilitas proses berdasarkan COBIT 5, TVRI Jayapura pada bagian pemberitaan Kota Jayapura telah ada pada level 3 Established Process.

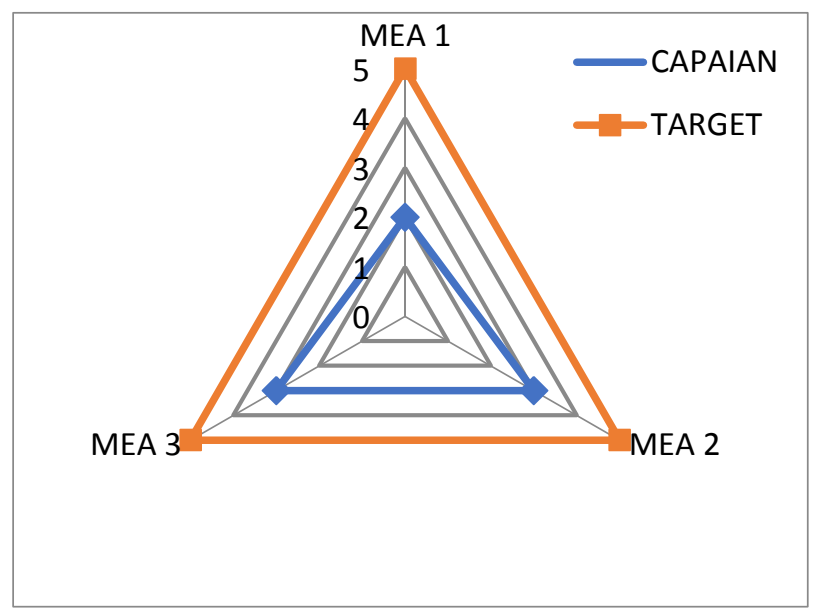

Gambar 3. Spider Chart Tingkat Kematangan

Pada gambar 2 Spider Chart menjelaskan tingkat kematangan sekarang. MEAO1 (Monitor, Evaluate, and Assess Performance and Conformance) berada pada tingkat kematangan level 2 Managed Process karena pada bidang pemberitaan TVRI Jayapura prosesnya telah teratur dalam penggunaan FileZilla sebagai teknologi informasi sejauh ini berjalan dengan baik namun ada kendala yang kadang terjadi seperti hilangnya jaringan internet sehingga aplikasi tidak dapat digunakan. Solusi pegawai ketika terjadi kendala hilangnya jaringan internet biasanya menggunakan jaringan hotspot seluler pribadi untuk menjalankan aplikasi tersebut.

MEA02 (Monitor, Evaluate and Assess the System of the Internal Control) berada pada tingkat kematangan level 3 (Established Process) pengendalian terhadap TVRI Jayapura bidang pemberitaan sepenuhnya berjalan sesuai dengan strategis organisasi Tugas Pokok dan Fungsi (Tupoksi). Pengolahan maupun penggunaan aplikasi tidak semua pegawai bisa melakukan akses FileZilla pengolahan harus yang memiliki username dan password. MEAO3 (Monitor, Evaluate, and Assess Compliance with External Requirements) berada pada tingkat kematangan level 2 (Managed Process) untuk proses bisnisnya berjalan sesuai strategis pada TVRI Jayapura bidang pemberitaan. Proses TI dan proses bisnis TI dengan hukum serta kebijakan yang diberlakukan telah standar dilakukan juga pada aplikasi yang digunakan.

Berikut tingkat kematangan juga kesenjangan yang dapat dilihat pada tabel 5, dimana sub-domain MEAl berada pada level 2 dari yang di harapkan 5 dan kesenjangannya adalah $3, M E A 2$ berada di level 3 dari yang diharapkan 5 dan kesenjangannya 2, MEA3 berada di level 3 dari yang diharapkan 5 dan kesenjangannya 2 .

Tabel 5. Tingkat Kesenjangan \& Kematangan

\begin{tabular}{|c|c|c|c|}
\hline \multirow{2}{*}{ Domain } & \multicolumn{3}{|c|}{ Level kematangan } \\
\cline { 2 - 4 } & $\begin{array}{c}\text { Saat } \\
\text { Ini }\end{array}$ & Diharapkan & $\begin{array}{c}\text { Kesenjangan } \\
\text { (diharapkan - saat } \\
\text { ini) }\end{array}$ \\
\hline MEA 1 & 2 & 5 & $5-2=3$ \\
\hline MEA 2 & 3 & 5 & $5-3=2$ \\
\hline MEA 3 & 3 & 5 & $5-3=2$ \\
\hline
\end{tabular}

Dari tingkat kematangan yang didapatkan peneliti menggunakan COBIT 5 dengan domain MEA, ditemukan beberapa kekurangan yang belum memenuhi kriteria. Maka dari itu peneliti membuatkan rekomendasi bagi TVRI Papua yang di rujuk pada tabel 6 rekomendasi 
Tabel 6. Tabel Rekomendasi

\begin{tabular}{|c|c|c|}
\hline Domain & Kelemahan & Rekomendasi \\
\hline $\begin{array}{l}\text { MEA } 1 \text { (Monitoring, Evaluasi } \\
\text { dan Penilaian Kinerja dan } \\
\text { Kesesuaian) }\end{array}$ & $\begin{array}{l}\text { Kurangnya pemahaman atau cara } \\
\text { penggunaan aplikasi FileZilla }\end{array}$ & $\begin{array}{l}\text { Dibutuhkan sosialisasi/pelatihan lagi } \\
\text { terhadap pegawai. }\end{array}$ \\
\hline $\begin{array}{l}\text { MEA } 2 \text { (Monitoring, Evaluasi } \\
\text { dan Penilaian Sistem Kontrol } \\
\text { Internal) }\end{array}$ & $\begin{array}{l}\text { Control internal sendiri sudah baik dalam } \\
\text { infrastruktur IT namun dalam Control } \\
\text { penggunaan IT sendiri masalah tergolong } \\
\text { mudah di akses siapa saja dan itu sangat } \\
\text { risiko jika ada file yang tidak seharusnya } \\
\text { masuk dalam media pemberitaan }\end{array}$ & $\begin{array}{l}\text { Perlu diadakannya aturan yang jelan akan } \\
\text { siapa saja yang berhak dalam } \\
\text { menggunakan PC admin ruang } \\
\text { Pemberitaan dan juga aplikasi FileZilla } \\
\text { atau sebut saja aturan yang memantau } \\
\text { aktivitas. pegawai }\end{array}$ \\
\hline $\begin{array}{l}\text { MEA } 3 \text { (Monitoring, Evaluasi } \\
\text { dan Penilaian Kepatuhan dan } \\
\text { Persyaratan Eksternal) }\end{array}$ & $\begin{array}{l}\text { Kaku nya fleksibilitas dalam pemberitaan } \\
\text { yang terlalu di kekang oleh } \\
\text { aturan/hukum/kebijakan yang dimana } \\
\text { berdampak pada rating TVRI itu sendiri } \\
\text { dan juga pegawai yang kurang dapat } \\
\text { bergerak dalam mengambil serta } \\
\text { menayangkan berita-berita yang ada }\end{array}$ & $\begin{array}{l}\text { Untuk di sini sudah sangat baik dan patuh } \\
\text { akan hukum yang berjalan atau kebijakan- } \\
\text { kebijakan yang ada, mungkin harus ada } \\
\text { perubahan beberapa kebijakan karena } \\
\text { terlihat kaku terhadap berita apa saja yang } \\
\text { bisa/boleh di siarkan (contoh pemilu) }\end{array}$ \\
\hline
\end{tabular}

\section{KESIMPULAN}

Berdasarkan hasil penelitian dan pembahasan yang peneliti lakukan melalui wawancara di TVRI Jayapura tahun 2020 dapat disimpulkan bahwa TVRI Jayapura telah mencapai standar yang di tetapkan. berdasarkan data yang diperoleh menghasilkan tingkat maturity level yang berbeda-beda, dimana MEAO1 (Monitoring, Evaluasi dan Penilaian Kinerja dan Kesesuaian), berada pada tingkat kematangan level 2 Managed Process bahwa kinerja TI-nya sudah standard dan berjalan dengan baik, MEA02 (Monitoring, Evaluasi dan Penilaian Sistem Kontrol Internal), berada pada tingkat kematangan level 3 Established Process bahwa pengendalian sepenuhnya berjalan sesuai dengan strategis organisasi Tugas Pokok dan Fungsi (Tupoksi), MEA03 (Monitoring, Evaluasi dan Penilaian Kepatuhan dan Persyaratan Eksternal), berada pada tingkat kematangan level 2 (Managed Process) dimana proses TI maupun proses bisnis sesuai dengan hukum serta kebijakan yang ada.

\section{SARAN}

Agar meningkatkan lagi kematangan TI pada TVRI Jayapura diharapkan adanya pelatihan bagi pegawai juga adanya pembagian tugas dan tanggungjawab serta aturan yang transparan bagi setiap pegawai. Dengan demikian kinerja pegawai menggunakan TI akan sangat mudah dan membantu di instansi tersebut.

\section{DAFTAR PUSTAKA}

Ajismanto, F. (2018). Analisis Domain Proses COBIT Framework 5 Pada Sistem Informasi Worksheet (Studi Kasus: Perguruan Tinggi STMIK, Politeknik Palcomtech). CogITo Smart Journal, $3(2)$, 207. https://doi.org/10.31154/cogito.v3i2.75.207-221

Haryono, R. C. S. (2019). Analisis Dan Penilaian Teknologi Informasi Pada Proses Tata Kelola Dengan COBIT 5 Pada Domain Edm Studi Kasus Universitas Peradaban. Indonesian Journal of
Business Intelligence (IJUBI), 1(1), 25. https://doi.org/10.21927/ijubi.v1i1.876

Pasha, D., Priandika, A. thyo, \& Indonesian, Y. (2020). Analisis Tata Kelola It Dengan Domain Dss Pada Instansi Xyz Menggunakan COBIT 5. Jurnal Ilmiah Infrastruktur Teknologi Informasi, 1(1), 7 12. https://doi.org/10.33365/jiiti.v1i1.268

Pertama, P. P. G., \& Ardiyasa, I. W. (2019). Audit Keamanan Sistem Informasi Perpustakaan STMIK STIKOM Bali Menggunakan Kerangka Kerja COBIT. Jurnal Sistem Dan Informatika, 13(2), 7786.

Pramita Ady, C. I., Basuki, P. N., \& Manuputty, A. D. (2019). Analysis of Information Technology Governance Using the COBIT 5 Framework (Case Study: E-Legal Drafting Legal Section of the Regional Secretariat of Salatiga City). Journal of Information Systems and Informatics, 1(2), 136151. https://doi.org/10.33557/journalisi.v1i2.17

Prasojo, H. P., \& Pujiono. (2017). Analisis Tata Kelola Teknologi Informasi Dengan Menggunakan Framework COBIT 5 Domain DSS01 ( Manage Operations ) Pada BPS Provinsi Jawa Tengah. Journal JOINS Udinus, 1(x), 67-76.

Rahayu, I. P., \& Agitha, N. (2019). Analisis Tata Kelola Teknologi Informasi Menggunakan Kerangka Kerja COBIT 5 (studi Kasus: DISKOMINFO Lombok Barat). Jurnal Teknologi Informasi, Komputer, Dan Aplikasinya (JTIKA ), 1(2), 131140. https://doi.org/10.29303/jtika.v1i2.23

Rumere, H. M., Tanaamah, A. R., \& Sitokdana, M. N. N. (2020). Analisis Kinerja Tata Kelola Teknologi Informasi Pada Dinas Perpustakaan Dan Kearsipan Daerah Kota Salatiga Menggunakan Framework COBIT 5.0. Sebatik, 24(1), 14-21. https://doi.org/10.46984/sebatik.v24i1.926

Suharto, A. H. H. S. A. (2016). Evaluasi Tata Kelola Teknologi Informasi Dengan Freamwork COBIT 5. $12,82-89$.

Suryono, R. R., Darwis, D., \& Gunawan, S. I. (2018). 
Audit Tata Kelola Teknologi Informasi Menggunakan Framework COBIT 5 (Studi Kasus:

Balai Besar Perikanan Budidaya Laut Lampung). Jurnal Teknoinfo, 12(1), 16. https://doi.org/10.33365/jti.v12i1.38

Umar, R., Riadi, I., \& Handoyo, E. (2019). Analisis Keamanan Sistem Informasi Berdasarkan Framework COBIT 5 Menggunakan Capability Maturity Model Integration (CMMI). Jurnal Sistem Informasi Bisnis, 9(1), 47. https://doi.org/10.21456/vol9iss1pp47-54

Wiraniagara, A., \& Wijaya, A. F. (2019). Analisis Tata Kelola Teknologi Informasi Menggunakan Framework COBIT 5 Domain Deliver Support and Service (Studi Kasus: Yayasan Eka Tjipta). Sebatik, 23(2), 663-671. https://doi.org/10.46984/sebatik.v23i2.831 